\title{
Notes
}

\section{Selective Hybridization of Dendron-Cyclodextrin Nanotubes with Metal Nanoparticles}

\author{
Chiyoung Park, Moon Sup Im, Jeonghun Lee, Yoon Soo Ko, and Chulhee Kim \\ Department of Polymer Science and Engineering, Inha Universitw, Incheon t02-751, Korea. ${ }^{*}$ E-mail: chkainha act kr \\ Received September 1+. 2009, Accepted September 25, 2009
}

Key Words: Dendron. Fluorescent nanotube. Self-assembly

The controlled organization of organic moieties with inorganic elements provides not only unique complex hybrid nanostructures but also sy nergistic functional properties. ${ }^{1 \cdot 3}$ For this purpose. several synthetic approaches have been developed by using organic supramolecules as a template for the construction of organized organic-inorganic hybrid architectures ${ }^{4-12}$ In addition the electronic or chemical communication between organic and inorganic moieties would provide an opportunity to produce unique functional hybrids. ${ }^{13.14}$ In particular. organic nanotubes have attracted considerable attention as a template for nanohybrids. ${ }^{3.15 .16}$ for examples. lipid nanotubes for the template of silica ${ }^{3.15}$ and peptide nanofibers for the template of biomineralization. ${ }^{5.9 .11}$ In particular, fabrication of linear assemblies of inorganic elements is of great interest for the development of nano-devices due to their anisotropic properties in 1-dimensional state. ${ }^{165}$ For that purpose carbon nanotubes are excellent template for the fabrication of linear assembly of inorganic elements. ${ }^{17,18}$ In addition. biomolecules such as DNA. ${ }^{19}$ peptides ${ }^{16}$ and vinuses ${ }^{210}$ were used as a template for the organization of nanoparticles. Self-assembled organic nanotubes are particularly advantageous as a template for the linear organization of nanoparticles because the surface anchoring functionality can be efficiently tailored.

Recently, we reported on the cyclodextrin-covered organic nanotubes (Den-CD-NTs) constnicted by the self-assembly of the amide dendrons with the focal pyrene unit which is included into the cavity of $\beta$ - or $\gamma-$ cyclodextrin $(C D)^{21,22}$ The narrow rim of CDs is exposed to the surface of the tube. Therefore. the surface functionality of the tube can be controlled in a facile manner during the self-assembly process via the host-guest interaction between the amide dendron and CDs. Therefore. we reasoned that the tunable well-defined surface of Den-CD-NTs would be an effective template for growing inorganic nanoparticles which can electronically communicate with the pyrene moiety included in the cavity of $\mathrm{CDs}$ on the surface of the tube. This approach would provide a facile route to unique nanotube-nanoparticle hybrid sy'stems for nanoelectronics or biosensor applications. Herein we present a unique approach to produce the hybrid of organic nanotube and metal nanoparticle by using Den-CD-NTs as a template.

We have demonstrated that the amphiphilic amide dendrons can self-organize not only in organic phase but also in aqueous phase ${ }^{\text {it- }-28}$ In particular, amide dendron 1 with the focal py rene moiety in Figure 1 self-organizes into a vesicular structure in an aqueous phase. Addition of $\beta-C D$ into the vesicular solution of dendron 1 induces formation of Den-CD-NT of which the surface is covered with $\beta-C D{ }^{2 l}$ The $C-6$ functionality of on the narrow of CDs is then exposed to the surface of DenCD-NTs. This methodology provides a facile sy nthetic route to diverse Den-CD-NTs with a variety of surface functional groups. In order to introduce the anchoring sites for metal nanoparticles on the surface of Den-CD-NT, the control of the surface functionality of the tube is critical. Therefore the unique self-assembly characteristics of the dendron nanotube sy stem can be effectively utilized to introduce diverse surface anchoring groups by addition of C-6 functionalized CDs into the vesicular solution of dendron $1 . ?$

In order to decorate metal nanoparticles on the surface of the tubes, we prepared Den-CD-NTs with amine or carboxyl surface functionality. as the template for hybrids. by utilizing self-assembly of amide dendron 1 with CD 2 or 3 following the strategy described in Figure 2. Dendron 1 and CDs 2-3 were synthesized by the reference procedure ${ }^{\hat{1} 1 . .2}$ Addition of mono(6-amino-6-deoxy)- $\beta-C D$. 2, into the vesicular solution of dendron 1 resulted in change of the pyrene fluorescence from the excimer enission at $+20-550$ num with an excitation at $345 \mathrm{~nm}$ to the monomeric emission at $370-420 \mathrm{~nm}$. as shown in Figure 3. by the formation of pyrene-CD inclusion complex, which then induced transformation of vesicle to the nanotube with the amine functionality on the surface (Den- $\mathrm{NH}_{2}-$ CD-NT). The outer diameter and wall thickness of Den- $\mathrm{NH}_{2}$ -

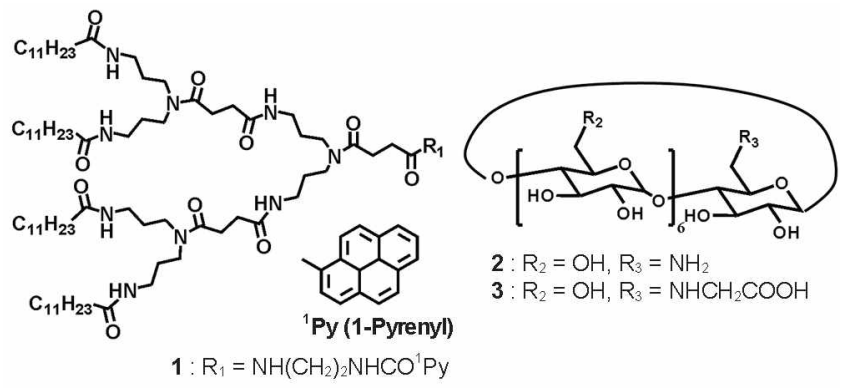

Figure 1. Chemical structures of amide dendron and cyclodextrins. 
CD-NT are approximately $40 \mathrm{~nm}$ and $10.5 \mathrm{~nm}$. respectively. ${ }^{22}$ In addition, the carboxyl-functionalized nanotube, Den-COOl [CD-NT. also was prepared by addition of CD 3, monol6-carboxymethy lamino-6-deoxy)- $3-(D$. into the vesicular solution of dendron $1 .^{22}$ It should be noted that the surface functionality on [Den-CD-NTs ean be precisely controlled by our method.

The anionic or cationic precursor of metal nanoparticles then can be adsorbed on the surface of Den- $\mathrm{NH}_{2}-\mathrm{CD}-\mathrm{NT}$ and Den-COOH-CD-NT templates via electrostatic interactions under appropriate conditions as shown in Figure 2. Subsequent reduction would give rise to lomation of the nanopartick on the surface of Den-CD-N'l. The tubes with different surface lunchional groups exhibiled selective adsorption behaviour towards different metal nanoparticle precursors, as described here for $P^{2} t$ and $\Lambda \mathrm{g}$ nanoparticles.

The nanolube with cationic surface (zeta potential $0.96 \mathrm{mV}$ ). Den-NI $I_{2}-\mathrm{CD}-\mathrm{Nl}$. can accommodate anionic metal precursors. Den- $\mathrm{NH}_{2}-\mathrm{CD}-\mathrm{NT}$ covered with $\mathrm{P} 1$ nanoparticulate clusters ( $\mathrm{Pt} / \mathrm{L}$ en- $\mathrm{NH}_{2}-\mathrm{CD}-\mathrm{N}^{\prime} \mathrm{l}$ ) was efficiently prepared with high specilicity. Briclly. an aclueous solution of $0.4 \mathrm{mM} \mathrm{K}{ }_{2} \mathrm{P}_{1 \mathrm{Cl}}$. was added into the adueous solution of $\mathrm{T}$ en- $-\mathrm{NH}_{2}-\mathrm{C} \cdot \mathrm{D}-\mathrm{NT}$. and then the metal precursor was reduced by addition of the aqueous solution of $\mathrm{NaBH}_{4}(0.6 \mathrm{~m}$. $20 \mu \mathrm{I})$. The P1/Den-NH $-\mathrm{CD}-\mathrm{N} T$ hybrid could be visualized with TEM (Figure 3 a). The EDX

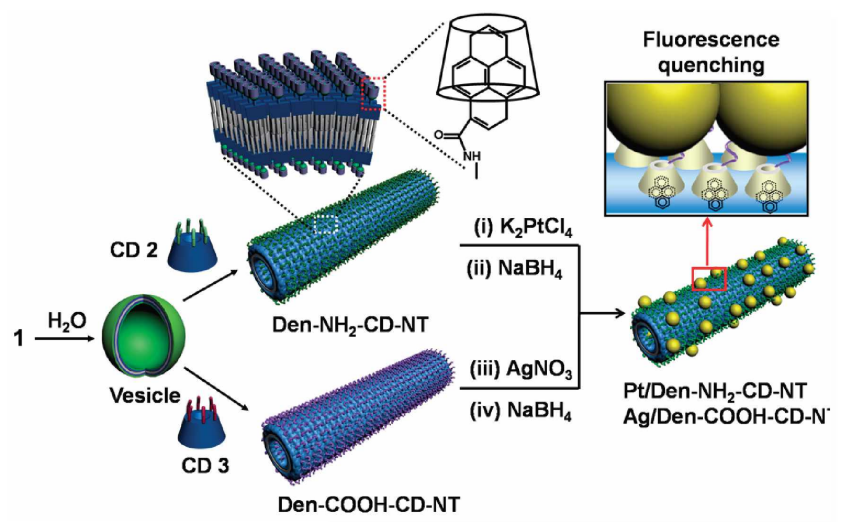

Figure 2. Schematic description for the preparation of organicinorganic nanohybrids.

analysis indicales the presenes of Pt. C. N. and O on the PV Den-N] I - -CD-NT hybrid (Figure 3b). The electron diffraction pattern in Figure $2 \mathrm{a}$ revealed the crystalline nature of the $\mathrm{Pt}$ Den- $\mathrm{NH}_{2}-\mathrm{CD}-\mathrm{NT}$ hybrid. As shown in Figure $3 \mathrm{c}$. the lormation of Pt nanoparticle on Den-NH I-C.D-N I gave rise to fluoresecence quenching of the pyrene emission from Pt/Den- $\mathrm{NH}_{2}-$ CD-NT.

Metal cations can be adsorbed on the anionic surlace of Den-COOH-CD-NT (cta polential $-14.36 \mathrm{mV}$ ) to form nanotube-nanoparticle hybrid by subsequent reduction. For this purposi. cationic silver precursor. AgNO, $(0.1 \mathrm{mM} .25 \mu \mathrm{L})$. was added into the Den-COOII-CD-N'] solution, and then the mixlure was reduced by $\mathrm{NaBH}_{4}(0.2 \mathrm{mM}, 10 \mu \mathrm{I})$. As shown in the TE.M image in Figure 4a. $\Lambda \mathrm{g}$ nanoparticles were attached on the surface of Den-COOH-CD-VI $(\Lambda \mathrm{g} / \mathrm{L}$ en-COOH-CDNT). The mean diamater of Ag nanoparticle was $8.8 \pm 2.4 \mathrm{~nm}$ (Figure $4 \mathrm{~b}$ ). The EDX analysis confirmed the presence of $\Lambda \mathrm{g}$.

(a)
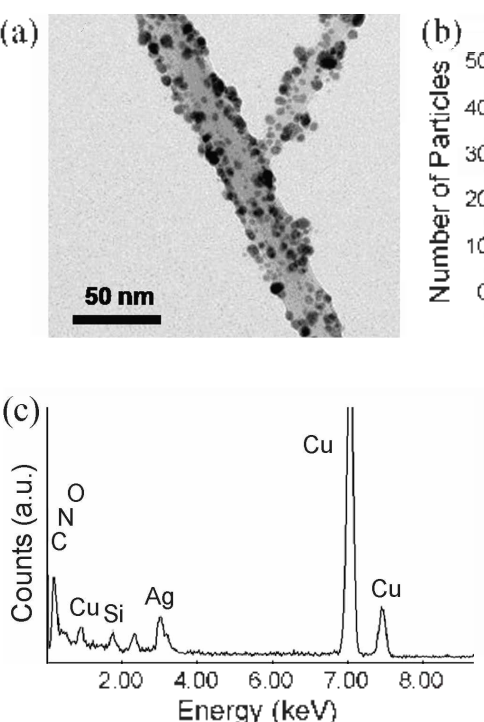

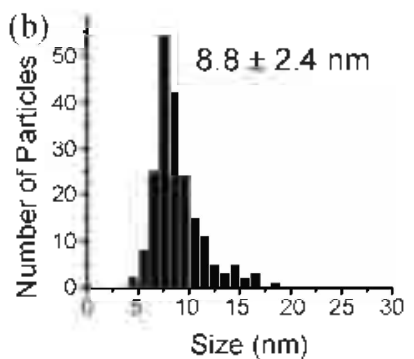

(d) Den-COOH-CD-NT

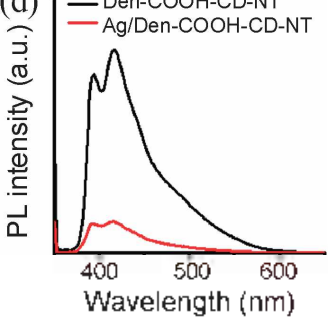

Figune 4. (a) TFM image of Ag/Den-COOH-CD-NT. (b) Size distribution of $\mathrm{Ag}$ nanoparticles on $\mathrm{Ag} / \mathrm{D}$ en-COOH-CD-NT. (c) F.DX spectrum of $\mathrm{Ag} / \mathrm{Den}-\mathrm{COOH}$-CD-NT. (d) Fluorescence spectra of DenCOOH $[-C D-N T$ and $\Lambda \mathrm{g} / \mathrm{Den}-\mathrm{COOI}-\mathrm{CD}-\mathrm{NT}$. The $\mathrm{\Lambda g}$ precursor was reduced by addition of the aqueous solution of $\mathrm{NaBH}_{4}(0.2 \mathrm{~mL} \mathrm{M} .10$ $\mu \mathrm{l}$.).

(a)

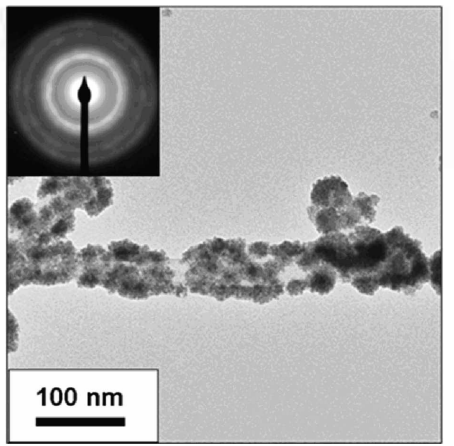

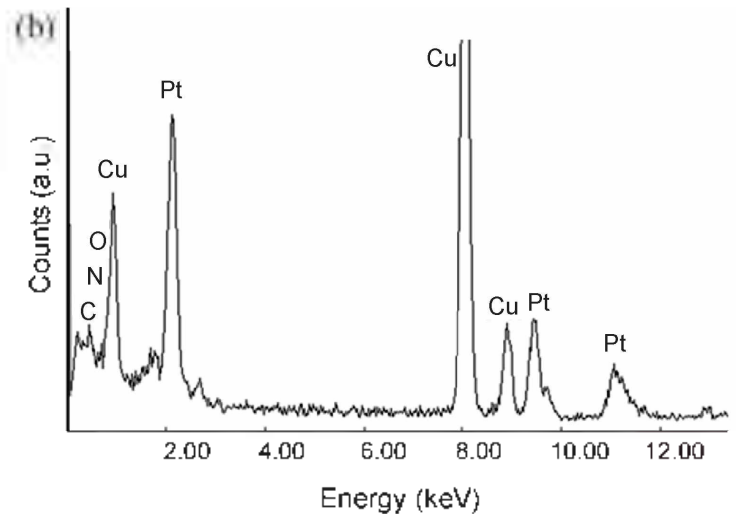

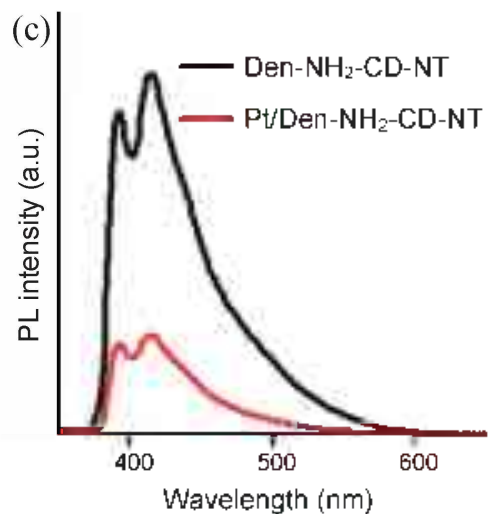

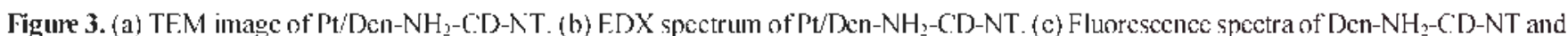
$\mathrm{Pt} / \mathrm{Den}-\mathrm{NH}-\mathrm{CD}-\mathrm{NT}$ 
(a)
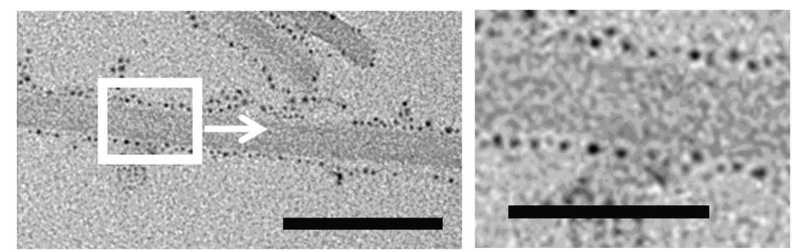

(b)
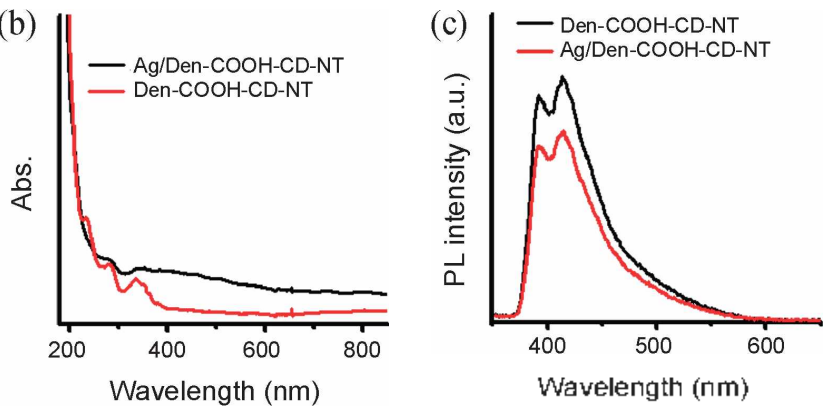

Figure 5. (a) TEM images of $\mathrm{Ag} / \mathrm{Den}-\mathrm{COOH}-\mathrm{CD}-\mathrm{NT}$ (scale bar: 100 $\mathrm{mm}$ and $50 \mathrm{~mm}$, respectively). (b) Absorption spectra of Den-COOHCD-NT and AgiDen-COOH-CD-NT. (c) Fluoreseence spectra of Den-COOII-CD-NI and AgiDen-COOII-CD-N']" The Ag precursor was reduced by addition of the aqueous solution of $\mathrm{NaBl} I-(0.1 \mathrm{mM}$, $2 \mu \mathrm{L})$

$\mathrm{C}, \mathrm{N}$, and $\mathrm{O}$ on $\Lambda \mathrm{g} / \mathrm{Den}-\mathrm{COOH}-\mathrm{CD}-\mathrm{NT}$ (Figure $4 \mathrm{c}$ ). $\Lambda$ s shown in tigure $4 d$, we observed fluorescence quenching of pyrene emission in $\mathrm{Ag} / \mathrm{Den}-\mathrm{COOH}-\mathrm{C} \mathrm{C}-\mathrm{NT}$

Interestingly, the size of the Ag nanoparticle could be controlled depending on the amount of reducing agent. In case of adding smaller amount of $\mathrm{NaBH}_{+}$aqueous solution $(0.1 \mathrm{mM}$. $2 \mu \mathrm{I}$ ), Ag nanoparticles with average diameter of about $2-3 \mathrm{~nm}$ were adsorbed on the Den-COOI l-CD-NT surface (Figure $5 \mathrm{a}$ ).

The enlarged image in figure 5a revealed that $\Lambda \mathrm{g}$ nanoparticles were arranged into an ordered one-dimensional array on the nanotube surface. The lateral distance between the silver nanoparticles was approximately $3 \mathrm{~nm}$. The UV-vis spectrum showed a broad surface plasmon band around 400 $550 \mathrm{~mm}$, characteristies of metallic silver manoparticle (Figure 5b). The fluorescence spectra in Figure 5c showed that the pyrene emission was slightly quenched in $\mathrm{Ag} / \mathrm{Den}-\mathrm{COOH}$ CD- $\mathrm{N}$ T. The control experiment with cationic silver precursor. $\mathrm{AgNO}_{3}$, by using $\mathrm{Den}-\mathrm{NH}_{2}-\mathrm{CD}-\mathrm{Nl}$ with cationic surface as a template did not produce silver nanoparticles on the surface of the tube. This result indicates that the carboxyl moiety of Den-COOH-CD-N'] was the anchoring site for the cationic precursor of silver nanoparticles.

In conclusion, the self-assembled Den-CD-NTs are effective templates for constructing the nanotube-nanoparticle hybrid by control of the surface functionality of the tube. The ionic metal precursors are adsorbed selectively on the cationic or anionic surface of Den-CD-NTs through electrostatic interaction, and then metal nanoparticles are formed on the nanotubes by subsequent reduction. The unique surface engineering approach for self-assembled Den-CD-NTs realized that the Den-CD-NTs with different surface functional groups exhibited selective adsorption behaviour towards different metal nanoparticles. 'I he hybridization of Den-CD-Nl's with metal nanoparticles brought about not only unique self-assembled structure but also electronic communication belween them. The fluorescence emission from the pyrene moiety of the nanotube was quenched due to the proximity between the pyrene moicty included in CDs and the metal nanoparticles on the surface. This approach would provide a unique route to multifunctional nanotube platforms. We are currently investigating the biosensory function of the nanoparticle-nanotube hybrids.

Acknowledgments. This work was supported by Inha University (2009).

\section{References}

I. Boettcher, S. W.: Fan, J.: Tsung, C.-K.; Shi, Q.: Stucky, G. I). Ace: (hem. Res. $2007,40.784$

2. Bommel, K. J. C. V.; Friggeri, A.; Shinkai, S. Angew. ('hem. Int. fid. 2003, 42.980.

3. Thou, Y, Shimizu, T'. ('hem. Huter 2008, 20,625

4. Kisailus, D.: Truong. Q: Amemiya, Y.: Weaver, J. C.: Morse, D.

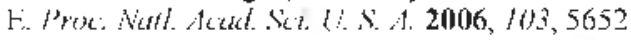

5. Hartgerink, I. D.; Beniash, E: Stupp, S. I. Scrfte' 2001, 294, 1684

6. Reches, M: Gacit, E. Sicfofte $\mathbf{2 0 0 3}, 30 \%, 625$

7. Mulvihil], M. J.: Rupert, B. L: He, R.: Hochbaum, A: Arnold, J: Yang, P. J. Am. (hem. iec. 2005, 127, 16040.

8. Cha, I. N.; Stucky, G. D.: Morse, D. E.; Deming. T. I. Nomme? 2000, 403,289

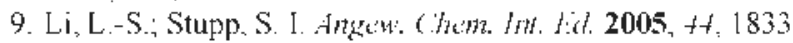

10. Waren, S. C.: DiSalvo, F. J.: Wiesner, U. Nut. Wut 2007, 6. 156.

11. Sone, H. D); Zubarev. H. R.: Slupp, S. I. Anger: (hom. Int. Id. $2002,+1,1705$

12. Kimura, M.: Kobayashi, S.; Kuroda, T., Fanabusa, K.: Shirai, II. Act. Mat. 2004, /6. 335

13. I lemikhuyzen, J. V.: George, S. J.: Vos, M. R. J.: Sommerdijk. N. A. I. M.: Ajayaghosh, A.; Meskers, S. C. I.: Schenning, A. P. 1. J. Anger $($ hem. Int. Id. 2007, 46, 1825

14. Vos, M. R. J.: Jard, G. E.; Pallas, A. L.: Breurken, M.; Asselen, O. L. I. V.; Bomans, P. H. H.: Loclre, P. E. L. G.; Froderik, P. M: Nolte, R. J. M.; Sommerdijk. N. A. J. M. /. Am. (hem. Soc. 2005, 127,16768

15. Shimizu, T.; Minamikawa, M. M. H. (hen. Rev. 2005, /1)5, 1401

16. Sharma, N.: Top, A.: Kiick, K. L.: Pochan, D. J. Angen: ('hem. In. id. $2009,+\infty, 7078$.

17. Ajayan, P. M. : lijima, S. Nattme 1993, 361, 333.

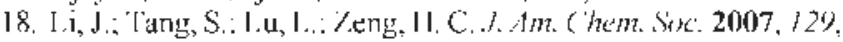
9401.

19. Sharna, J.: Ke, Y.: I.in, C.: Chhabra, R: Wang, Q.: Nangreave,

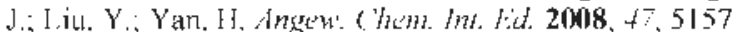

20. Nam, K. T.; Kim, D.-W.; Yoo, P. J.; Chiang, C.-Y, Methong. N.: I lanmond, P. [?: Chiang, Y.-M.: Belcher, A. M. Serence $2006,3 / 2,885$

21. l'ark, C: l,ee I. II: Lee, S; Song, Y: Rhue, M: Kim, C. Proc.

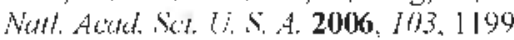

22. Park, C. Im, M. S ; Lec, S: Lim, J.; Kim, C. Anger ; ( $\mathrm{km}$. Int. 1.d. $2008,+7,9922$.

23. Icon. H.-I.; Kang, M. K.: Park, C.; Kim, K. T.: Chang. J. Y.: Kim, C.: Song, H. H. I.amgmuir 2007, 23, 13109.

24. Kim, C: Kim, K. T. Chang, Y : Song, H. H.: Cho, T.-Y.; Jeon, H.-I. J. Am. ( $/ k m$. Sis: 2001, I23,5586

25. Kim, C.: Lec, S. J : L L, I. H.: Kim, K. T.; Song, H. H.; Jcon, 11.-I. (hem. Muter: 2003, /5,3638

26. Ko, H. S.: Park, C.: I.ee, S. M.: Song, II. II: Kim, C. (hem. Hater. 2004, 16, 3872

27. Park, C.: Choi, K. S.: Song, Y.: leon, 11.-I.: Song, ]1. I1.: Chang, J. Y.: Kim. C. Jumgmm 2006, 22,3812.

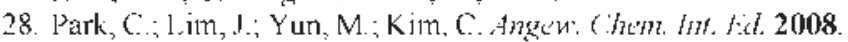
47.2959 